\section{Kesediaan Guru Pendidikan Khas dalam Melaksanakan Mata Pelajaran Asas Tanaman}

\section{Nurul Farahah Derapa, Suziyani Mohamed}

Universiti Kebangsaan Malaysia, 43600 Bangi, Selangor, Malaysia. Email: nurulfarahahderapa@gmail.com

Abstrak: Kurikulum Standard Sekolah Menengah Pendidikan Khas (KSSM PK) dilaksanakan awal tahun 2017. Mata pelajaran Asas Tanaman adalah satu daripada tujuh mata pelajaran yang terdapat $\mathrm{d}$ dalam Kemahiran Asas Vokasional. Terdapat tiga objektif kajian iaitu untuk mengenal pasti kesediaan guru dalam aspek pengetahuan, kemahiran dan sikap dalam melaksanakan pengajaran Asas Tanaman, kehadiran kursus Asas Tanaman serta mengenal pasti perbezann kemahiran guru dalam berdasarkan pengajaran Ass Tanas pendekatan kuantitatif ini melibatkan 60 orang guru yang dipilih dalam kalangan guru pendidikan khas yang mengajar mata pelajaran Asas Tanaman di Program Pendidikan Khas Integrasi. Data dikumpulkan menggunakan satu set soal selidik yang mengandungi 49 item. Soal selidik tersebut dibina berdasarkan skala likert lima mata. Data yang diperolehi dianalisis menggunakan perisian SPSS. Analisis statistik deskriptif dan inferensi digunakan untuk mendapatkan maklumat yang diperlukan berdasarkan persoalan kajian. Hasil keseluruhan dapatan kajian mendapati tahap pengetahuan, kemahiran dan sikap adalah inggi $($ Min $=4.11)$ Tidak terdapat perbezaan yang signifikan kemahiran guru dalam melaksanakan Terdapat perbezaan yang signifikan bagi kesediaan pengetahuan guru berdasarkan kehadiran kursus Asas Tanaman $(\mathfrak{p}<0.05)$. Kajian ini dapat membantu Kementerian Pendidikan Malaysia dalam menyediakan kursus latihan kepada guru untuk menambahkan pengetahuan dan kemahiran dalam melaksanakan pengajaran Asas Tanaman. Perlaksanaan pengajaran Asas Tanaman yang berkesan dapat melahirkan murid berkeperluan khas masalah pembelajaran yang mempunyai pengetahuan dan kemahiran dalam bidang pertanian.

Kata kunci: KSSM Pendidikan Khas, Asas Tanaman, Program Pendidikan Khas Integrasi, Pengetahuar guru, Sikap guru, Kemahiran guru

Kurikulum Standard Sekolah Menengah (KSSM) Pendidikan Khas diperkenalkan pada tahun 2017 bagi mengambil kira pendidikan yang sesuai d relevan dengan ketidakupayaan yang dialami ole murid Berkeperluan Khas (MBK). Kurikulum in menyediakan peluang untuk MBK mempelajari dan menguasai pengetahuan dan kemahiran vokasiona serta menyediakan mereka ke arah transisi kerjaya. Dalam kurikulum ini terdapat Kemahiran Asa Vokasional yang disediakan untuk MBK berkefungsia sederhana di tingkatan satu di Program Pendidika Khas Integrasi (PPKI). Terdapat tujuh mata pelajara dalam Kemahiran Asas Vokasional antaranya iala Asas Masakan, Asas Jahitan, Asas Tanaman, Asas Akuakultur, Asas Multimedia, Asas Refleksologi da Asas Pembuatan Perabot. Sekolah boleh memilih untuk melaksanakan salah satu atau kedua-dua mata pelajaran tersebut. Dalam kajian ini mata pelajaran Asas Tanaman (AT) dipilih oleh pengkaji untuk melaksnakan kajian berdasarkan objektif yang tela ditentukan. Antara objektif utama AT ialah untuk melahirkan murid yang mempunyai pengetahua dan kemahiran dalam Asas Tanaman serta memberi peluang kerjaya kepada mereka. Murid yang berjaya menghabiskan modul sehingga tingkatan lima aka diberikan Sijil Kem persekolahan. Sijil kemahiran ini sangat penting dan berguna kepada murid untuk bersaing dengan dunia luar dalam mendapatkan tempat di alam pekerjaan. Oleh itu kelangsungan pengajaran Asas Tanaman in perlu dipastikan agar tiada masalah dalam memastika objektif yang digariskan dapat dicapai dan member manfaat kepada MBK masalah pembelajaran.

Pengetahuan dan sikap yang tinggi sangat penting bagi seseorang guru dalam memastikan pengajaran berjalan dengan lancar dan dapat memberi kesan yang Mohd Salleh, Aliza Alias \& Zalizan Mohd Jela Mohd Salleh, Aliza Alias \& Zalizan Mohd Jela
(2012) yang menyatakan guru perlu mempunya kemahiran dan pengetahuan yang tingoi supaya dapat membantu murid MBK masalah pembelajaran dalam proses pengajaran dan pembelajaran semasa di sekolah. Strategi yang sesuai perlu digunakan bagi menarik minat murid dan membantu merek menguasai dalam mata pelajaran Asas Tanaman. Seseorang murid yang menujjukkan minat sewaktu proses pembelajaran akan mempengaruhi pencapaia terhadap penguasaan mata pelajaran tersebut (Airulliza 2012). Pengajaran yang berkesan adalah guru yang berpengalaman, berkemahiran dan berpengetahua dalam bidang pertanian. Tanggungjawab guru adalah meransang minda dan memberi pengetahuan kepad bagi mengembangkan minat dan kemahiran MBK
MBK masalah pembelajaran bagi memastikan mereka berjaya dalam akadenik, hidup berdikari dan dapa Zainon \& Mohd Zuri Ghani 2012).

Kesediaan guru dilihat sangat penting dalam konteks pelaksanaan pengajaran yang menjurus kepada proses inovasi dan mempengaruhi kejayaan atau kegagalan sesuatu pengajaran dalam bidang pendidikan (Nor Sakinah 2003, Abdul Rahman 2016). Jadi, usaha pihak Kementerian Pendidikan Malaysia (KPM) dalam memperkenalkan mata pelajaran Asas Tanaman ini adalah sebagai pengajaran yang menjurus kepada proses inovasi di PPKI. Hal ini selari dengan hasrat KPM melalui Bahagian Pendidikan Khas (BPK) untuk mengubah amalan pengajaran guru daripada bersifat chalk and talk kepada pengajaran yan berasaskan konstruktivisme selari dengan pendidikan abad ke- 21. Abdul Halim (2016) dalam kajiannya Kesediaan guru dalam aspek pengetahuan, kemahiran dan sikap dalam pengajaran Kemahiran Hidup Pertanian' di perak mendapati guru-guru mempunyai kesediaan pada tahap sederhana terhadap pengajaran Kemahiran Hidup Perkebunan di PPKI. Pembelajara entang kaedah yang digunakan (Jamilah 2016). Ha ni disokong oleh Ely (2009) menyatakan kewujudan kemahiran dan pengetahian dapat membantu menjayakan pelaksanaan sesuatu pengajaran yang menghasilkan inovasi dan sebagainya

Menurut Noor Aini, Zamri dan Zahara (2012) menyatakan guru pendidikan khas tidak kreatif untuk menangani masalah murid masalah pembelajaran teruk tanpa pertuturan. Masalah ini berlaku kerana guru-guru kurang bersedia dalam aspek kemahiran dan pengetahuan terhadap pengajaran yang menggunakan kaedah pengajaran konstruktivisme. Guru perlu melengkapkan diri dengan pengetahuan, pengalaman dan lathan yang mantap untuk menjadi agen perubahan bagi membantu MBK masalah pembelajaran dalam pendidikan (Mohd Razali 2008). Pengetahuan yang baik dapat membantu menambah keyakinan guru untuk membuat inovasi dalam pengajaran (Abdul Rahman, 2016). Pengetahuan sangat penting bag seorang guru unuk pengajeran dan pembelajaran yang bermakna. Hal ini kerana pengetahuan yang banyak akan memudahkan guru menggunakan strategi pengajaran yang sesuai dengan keupayaan dan tahap perkembangan murid. Secara kesimpulan, didapati kesediaan guru dalam aspek kenahiran da pengajaran Asas Tanaman yang berkesan dan berjaya.

Kesediaan guru adalah faktor utama dalam memastikan keberkesanan pengajaran yang dilakukan. Namun begitu terdapat beberapa kenyataan yang menyatakan kesediaan guru dari aspek pengetahuan, emahiran dan sikap masih kurang. Antaranya ialah Abdul Rahman (2016) menyatakan guru-guru tidak mendapat pendedahan yang secukupnya dalam bidang pertanian Manakala Mohd Rizal dan Muallimah Arshad (2010) menyatakan beberapa orang guru PPK KHP). Guru adalah sumber utama dalam sistem pendidikan kerana kejayaan dan kegagalan seseorang bergantung daripada sokongan dan peranan guru kepada murid. Proses pengajaran dan pembelajaran di Program Pendidikan Khas Integrasi akan menghadapi masalah apabila guru tidak berminat untuk mengajar dan sekaligus memberi kesan sampingan kepada murid dalam pencapaian akademik, keadaan kelas tidak terkawal dan murid hilang fokus terhadap pembelajaran Abdul Rahim Hamdan \& Ahmad Faizal Ayop (2012). Namun begitu, kajian-kajian sebelum ini masih tiada yang berkaitan dengan kesediaan guru dalam melaksanakan mata pelajaran Asas Tanaman. Dalam konteks ini pengkaji merasakan kajian ini patut dikaji bagi meninjau kesediaan guru dalam melaksanakan pengajaran Asas Tanaman. Tambahan agi, mata pelajaran ini masih baru.

\section{METODE}

Kajian ini merupakan kajian tinjauan menggunakan kaedah kuantitatif. Sampel kajian terdiri daripada 60 orang guru pendidikan khas yang mengajar mata pelajaran Asas Tanaman. Instrumen yang digunakan ialah soal selidik yang diadaptasi daripada daripada soal selidik Abdul Rahman (2016). Menurut Mitchell (1991) soal selidik adalah teknik yang paling sesuai dalam kajian yang berbentuk tinjauan. Terdapat beberapa item dalam soal selidik yang ubahsuai mengikut isi kandungan pengajaran Asas Tanaman dalam Kurikulum Standard Sekolah Menengah Khas. Soal selidik terdiri daripada dua bahagian iaitu Bahagian A: Demografi Responden, Bahagian B: pengetahuan guru terhadap pengajaran Asas Tanaman, Bahagian C: kemahiran guru terhadap pengan Aanaman dan Bahagian D. Sikap puru terhadap pengajaran Asas Tanaman. Item-item yang terdapat dalam Bahagian A mempunyai 2 soalan (enkan dengan maklumat demografi responden,

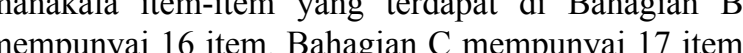
anpal 16 item, Bahagian C mempunyai 17 item dan Bahagian D mempunyai 13 item. Bahagian B, C likert lima mata. Kajian rintis juga telah dijalankan kagi memastikan setiap item soal selidik yang dibina bagi memastikan setiap item soal selidik yang dibina pekali kebolehpercayaan Alpa Cronbach's ialah 0.940. Kesahan pakar juga dilakukan oleh dua orang pensyarah yang berpengalaman lebih daripada 7 tahun dalam pendidikan khas dan mempunyai Doctor of philosophy. Soal selidik ditadbir sendiri oleh pengkaji dan diberikan masa untuk disiapkan dan dikutip semula. Seterusnya data yang diperolehi dianalis menggunakan perisian Statistical Package of the 
Tabel 1: Demografi

\begin{tabular}{lcc}
\hline Demografi & Kekerapan & (\%) \\
\hline Pengalaman & & \\
Mengajar & & \\
Kemahiran Hidup & & \\
Pertanian & & \\
1-5 Tahun & 34 & 56.7 \\
6-10 Tahun & 20 & 33.3 \\
11-15 Thanun & 3 & 5.0 \\
16 Tahun Dan Ke & 3 & 5.0 \\
Atas & & \\
Menghadiri kursus & & \\
Asas Tanaman & & \\
Ya & & \\
Tidak & 16 & 26.7 \\
& 44 & 73.3 \\
\hline
\end{tabular}

Tabel 2: Pengkelasan tahap berasaskan skor min

\begin{tabular}{ll}
\hline Tahap & Skor min \\
\hline Lemah & $1.00-2.33$ \\
Sederhana & $2.34-3.66$ \\
Baik & $3.67-5.00$ \\
\hline
\end{tabular}

Jadual 3: Tahap kesediaan guru dalam melaksanakan pengajaran Asas Tanaman dari aspek pengetahuan, kemahiran dan sikap

\begin{tabular}{llcl}
\hline No & Kesediaan Guru & Min & $\begin{array}{l}\text { Interpretasi } \\
\text { Skor }\end{array}$ \\
\hline 1 & Pengetahuan & 4.28 & Tinggi \\
2 & Kemahiran & 3.83 & Tinggi \\
3 & Sikap & 4.23 & Tinggi \\
\multicolumn{2}{l}{ Keseluruhan } & 4.11 & Tinggi \\
\hline
\end{tabular}

Science version 22.0 (SPSS 22). Analisis statistik deskriptif ini melibatkan analisis frekuensi, min do peratus manakala analisis inferensi melibatkan Ujia Mann Whitney dan Ujian Kruskal Wallis.

\section{HASIL DAN PEMBAHASANAN}

\section{Hasil}

Sebanyak 60 set soal selidik telah diedarkan kepada responden di PPKI sebuah negeri. Tabel 1 dibawah menunjukkan 60 orang responden mengikut demografi iaitu pengalaman mengajar Kemahiran Hidup Pertanian dan menghadiri kursus Asas Tanaman.

Jadual 1 menunjukkan bahawa pengalaman mengajar Kemahiran Hidup Pertanian, 34 orang mempunyai pengalaman mengajar $1-5$ tahun $(56.7 \%)$, 20 orang mempunyai pengalaman mengajar 6-10 tahu 15 to $), 3$ orang mempunyai pengalaman mengajar $11-$ mengajar 16 tahun ke atas (5.0\%). Berdasarkan menghadiri kursus Asas Tanaman, 16

orang (26.7\%) pernah menghadiri kursus Asas Tanaman dan 44 orang $(73.3 \%)$ tidak perna menghadiri kursus Asas Tanaman. Semua dapata diterjemahkan mengikut skala pengkelasan tahap daripada Mohd Majid Konting (1990) mengikut tig julat skala yang mewakili lemah, sederhana dan baik.

Kesediaan guru dalam aspek pengetahua erhadap pengaiaran Asas Tanamen menunjukkan 16 item yang dikaji berada pada tahap yang tingoi. Item yang mempunyai nilai min yang paling tinggi ialah item 13 iaitu strategi Pdp perlu berpusatkan murid da berasaskan aktiviti $(M=4.46)$. Manakala item yang mempunyai min yang paling rendah ialah matlama AT melahirkan MBKMP yang berkemahiran dalam bidang akuakultur $(M=3.78)$. Secara keseluruhan menunjukkan bahawa kesediaan guru dari aspek pengetahuan terhadap pengajaran Asas Tanama berada pada tahap tinggi $(\mathrm{M}=4.28)$.

Kesediaan guru dalam aspek kemahiran dalam melaksanakan pengajaran Asas Tanaman menunjukkan daripada 17 item menunjukkan 3 item berada pada tahap sederhana dan 14 item berada pada tahap yang tinggi. Dalam kajian ini, item min yang tertingg murid $(\mathrm{M}=4.18)$ iaitu saya mahir dalam memastika menyiapkan tugasan dalam tempoh yang ditetapkan. Manakala item min yang terendah adalah ditetapkan. dalam menentukan antara soalan kandungan mah peperiksaan AT $(M=3.38)$. Secara keseluruhan menunjukkan kemahiran guru terhadap pengajara Asas Tanaman berada pada tahap tinggi $(\mathrm{M}=3.83)$

Kesediaan guru dari aspek sikap terhadap pengajaran Asas Tanaman mong sklkan 13 item mempunyai min yang tinggi $(\mathrm{M}=4.60)$ saya yaki kerjasama dan perkongsian dan dapat memudahkan saya menjalankan pengajar Asas Tanaman di sekolah. Manakala item min yan paling renda $(\mathrm{M}=3.88)$ saya lebih bermotivas untuk menajor MBKMP dalm mata pelajan Asas Tanama Secara keseluruha menunjukkan kesedias con Tanaman berada pada taho tingi $(\mathrm{M}=4.23)$.

Secara keseluruhan dapat dirumuskan bahawa tahap kesediaan guru dari aspek pengetahuan kemahiran dan sikap guru pendidikan khas yang pada tahap tingoi $(M=4.11)$. Noshidah Salleh, Aliza pada tahap tinggi (M-4.11). Noshidah Salleh, Aliza mempuai pengetahun (20) (a) (1)

Dapatan kajian jadual 4 menunjukkan perbezaan pengetahuan guru terhadap pengajaran Asas Tanama berdasarkan kehadiran kursus Asas Tanaman.
Jadual 4: Perbezaan pengetahuan guru terhadap an berdasarkan kehadiran kursus Asas Tanaman

\begin{tabular}{|c|c|c|c|c|c|c|}
\hline $\begin{array}{l}\text { Kehadiran } \\
\text { Kursus } \\
\text { Asas } \\
\text { Tanaman }\end{array}$ & $\mathrm{N}$ & $\begin{array}{l}\text { Min } \\
\text { Ranking }\end{array}$ & $\begin{array}{l}\text { Jumlah } \\
\text { ranking }\end{array}$ & $\begin{array}{l}\text { Mann } \\
\text { whitney }\end{array}$ & $\mathrm{z}$ & Sig \\
\hline Ya & 16 & 43.09 & 689.50 & 150.500 & $\begin{array}{l}-3 . \\
387\end{array}$ & 0.00 \\
\hline Tidak & 44 & 25.92 & 1140.50 & & & \\
\hline
\end{tabular}

Signifikan pada aras $<0.05$

Jadual 5: Perbezaan kemahiran guru terhadap pengajaran Asas Tanaman berdasarkan
pengalaman mengajar Kemahiran Hidup

Pertanian

\begin{tabular}{lllllll}
\hline Item & $\begin{array}{l}\text { Pengalaman } \\
\text { mengajar } \\
\text { KHP }\end{array}$ & N & $\begin{array}{l}\text { Min } \\
\text { Ranking }\end{array}$ & $\begin{array}{l}\text { Chi } \\
\text { Square }\end{array}$ & df & Sig \\
\hline Kema & $1-5$ tahun & 34 & 27.38 & 7.225 & 3 & .065 \\
hiran & $6-10$ tahun & 20 & 35.05 & & & \\
& $11-15$ tatun & 3 & 17.67 & & & \\
& 16 tahun ke & 3 & 48.33 & & & \\
\hline & atas & & & & & \\
\hline
\end{tabular}

Signifikan pada aras $<0.05$

\section{Pembahasan}

Analisis mendapati bahawa terdapat perbezaan yang signifikan bagi pengetahuan guru berdasarkan kehadiran kursus Asas Tanaman ( $\mathrm{U}=150.50, \mathrm{~N} 1=16$, $\mathrm{N} 2=44, \mathrm{p}<0.05)$. Oleh itu, hipotesis nol adalah ditolak. Jadi, kehadiran ke kursus memainkan peranan yang penting dalam menambahkan pengetahuan guru
terhadap pengajaran Asas Tanaman. Guru yang hadir kursus Asas Tanaman lebih berpengetahuan dan mempunyai ilmu yang tinggi berbanding guru yang tidak hadir ke kursus yang dianjurkan. Dari segi min ranking menunjukkan guru yang pernah mengikuti kursus Asas Tanaman mempunyai pengetahuan yang lebih tinggi (min ranking $=43.09$ ) berbanding guru yang tidak pernah mengikuti kursus (min ranking $=25.92$ ). Ini menunjukkan guru yang menghadiri kursus lebih memahami isi kandungan dan objektif mata pelajaran Asas Tanaman kepada MBK masalah pembelajaran. Mereka juga mempunyai pengetahuan dalam menggunakan teknik dan kaedah pengajaran yang betul bagi melahirkan MBK masalah pembelajaran yang berpengetahuan dan berkemahiran dalam bidang pertanian.

Dapatan kajian jadual 5 menunjukkan perbezaan kemahiran guru terhadap pengajaran Asas Tanaman berdasarkan pengalaman mengajar Kemahiran Hidup Pertanian. Kemahiran Hidup Pertanian adalah mata pelajaran yang diajar dalam Kurikulum Bersepadu Sekolah Menengah sebelum KSSM diperkenalkan. Mata pelajaran ini berkaitan dengan pertanian sama seperti mata pelajaran Asas Tanaman. Oleh sebab itu pengkaji mengambil kira pengalaman guru yang

Dapatan kajian menunjukkan bahawa tidak terdapat perbezaan yang signifikan bagi kemahiran guru dalam melaksanakan pengajaran Asas Tanaman berdasarkan pengalaman mengajar Kemahiran Hidup Pertanian (KHP) dengan nilai chi square $=7.225$ dan $\mathrm{sig}=.065, \mathrm{p}>0.05$. Ini menunjukkan hipotesis nol adalah diterima. Oleh itu, pengalaman mengajar Kemahiran Hidup Pertanian tidak mempengaruhi kemahiran guru terhadap pengajaran Asas Tanaman. Dari segi min ranking menunjukkan bahawa guru berpengalaman mengajar 16 tahun ke atas (min ranking $=48.33$ ) mempunyai pengetahuan yang lebih tinggi diikuti dengan guru yang berpengalaman mengajar 6-10 tahun ( $\min$ ranking $=35.05$ ), guru yang berpengalaman mengajar $1-5$ tahun (min ranking $=27.38$ ) berbanding guru yang mempunyai pengalaman mengajar $11-15$ tahun (min ranking= 17.67). Kajian menunjukkan guru yang berpengalaman mengajar lebih lama Kemahiran Hidup Pertanian mempunyai kemahiran yang tinggi. Kemahiran Hidup Pertanian adalah mata pelajaran yang diajar sebelum mata pelajaran Asas Tanaman diperkenalkan. Pengajaran KHP adalah sama dengan Asas Tanaman iaitu berasaskan bidang pertanian, namun begitu terdapat beberapa objektif dan isi kandungan mata pelajaran yang sedikit berlainan. Akan tetapi guru yang sudah mempunyai pengalaman mengajar KHP dapat membantu dan memudahkan mereka mengajar mata pelajaran Asas Tanaman dengan baik. Ini juga disokong berdasarkan dapatan kajian lepas Noraini Khamis \& Aliza Alias (2016), Abdul Rahman (2016) \& Sairulbariah Ali (2017) yang menyatakan guru-guru yang berpengalaman mempunyai tahap kesediaan dari aspek pengetahuan, kemahiran dan sikap yang tinggi berbanding guru yang kurang berpengalaman.

\section{KESIMPULAN DAN SARAN}

\section{Kesimpulan}

Berdasarkan analisis kajian yang diperolehi, dapatan menunjukkan bahawa $100 \%$ responden mempunyai tahap pengetahuan, kenahiran dan sikap guru berada pada tahap tinggi. Walaupun begitu dik menunjukkan guruguru masih tidak bersodia delom pengajaran Asas Tanaman kepada MBK masalah pembelajaran kerana terdapat beberapa item dalam kemahiran guru yang berada pada tahap sederhana. Antaranya ialah guru kurang mahir dalam membina soalan Asas Tanaman, serta guru kurang mahir dalam menyediakan borang pentaksiran untuk menilai hasil kerja murid. Ini menunjukkan kemahiran guru masih perlu diperbaiki dan perlu diberikan perhatian bagi mengelakkan pembelajaran yang tidak berkesan. Tambahan pula, mata pelajaran ini masih baru diperkenalkan pada 2017 dan masih memerlukan 
penambahbaikan untuk mencapai objektif yang telah digariskan. Oleh itu program atau kursus perlu diberikan secukupnya supaya dapat memantapka lagi kesediaan guru dalam melaksanakan pengajara Asas Tanaman. Hal ini disokong oleh Norfadhila (2014) dan Mohd Hashim (2008) menyatakan bahawa bengkel dan latihan dapat meningkatkan pengetahuaa dan kemahiran guru. Latihan dalam perkhidmatan jug boleh dilaksanakan bagi meningkatkan kualiti sebaga seorang guru dalam melaksanakan pengajaran. Piha yang terlibat juga harus memikirkan langkah untuk melatih guru berdasarkan mata pelajaran Asas Tanam bagi meningkatkan kandungan kursus mereka.

Guru-guru masalah pembelajaran perlu mempelbagaikan kaedah dan teknik pengajaran dan menjadi kreatif supaya dapat menarik minat murid dalam pembelajaran (Norasmah dan Norfadhilah 2012 dan Norfadhilah 2014). Guru juga perlu mempunya sikap yang positif dalam diri supaya bersemang untuk mengajar dan mampu mencipta persekitara yang kondusif. Hal ini disokong oleh kajian Shahrin dan Siti Hasmah (2010) yang menyatakan guru yang mempunyai sifat positif sentiasa bersemangat dala pengajaran serta dapat mencipta persekitaran yang ceria. Jadi, sebagai seorang guru perlu mempunya pengetahuan, kemahiran dan sikap yang tinggi dala perancang pengajarn yang berkualiti. Romina et a (2010) dan Barnet (2010) menyatakan guru perlu berpengetahuan tinggi untuk mengendalikan pelbag kaedah dalam pengajaran. Begitu juga dengan Anne, M.Soc dan Liisa (2012) menyatakan latihan pedagog yang diberikan kepada guru mampu mengubah ca berfikir dan sikap guru ke arah yang lebih positi Seterusnya sampel dan lokasi kajian perlu diperluaska supaya dapat melihat tahap kesediaan guru terhadap pengajaran Asas Tanaman serta mengetahui kekanga yang timbul dalam melaksanakan pengajaran denga berkesan. Selain itu guru-guru perlu memainka peranan yang penting untuk menguasai isi kandungan mata pelajaran Asas Tanaman supaya dapat melahirkan MBK masalah pembelajaran yang mempunya pengetahuan dan kemahiran dalam bidang pertanian. Hal ini disokong oleh kajian Norshidah Mohd Salle Aliza Alias \& Zalizan Mohd Jelas (2012) yan menyatakan guru perlu mempunyai pengetahua

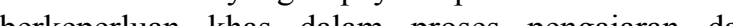
berkepertuan thas dalam proses pengajaran de pembelajaran

\section{Saran}

Kesediaan guru pendidikan khas dari aspek untuk memastikan perlaksanaan pengajaran Asa Tanaman dapat nemonui objektif yang ditetapk dalam KSSM Pendidikan Khas bagi melahirkan MBK masalah pembelajaran yang mempunyai pengetahua dan kemahiran dalam bidang pertanian. Penyediaan supaya perlu kreatif dan mencipta suasana pengajaran yang menyeronokkan supaya dapat menarik minat MB masalah pembelajaran belajar. Teknik penyampaia guru juga perlu diambil kira supaya memudahkan murid memahami isi pengajaran. Sekaligus membant murid mempunyai pengetahuan dan kemahiran dalan bidang pertanian. Selain itu perlaksanaan pengajara Asas Tanaman sangat penting kepada MBK masala pembelajaran bagi menyediakan mereka kearah transisi kerjaya apabila tamat alam persekolahan kelak. Kajian ini juga membantu pihak-pihak yang terliba membuat penambahbaikan supaya pengajaran dapa dilaksanakan dengan berkesan.

\section{DAFTAR RUJUKAN}

Abdul R. H., (2016). Kesediaan Pengetahuan Kemahiran dan Sikap Guru Pendidikan Khas Bermasalah Pembelajaran Mengajar Kemahiran Hidup Pertanian. Universiti Kebangsaa
Malaysia

nne, G.P, M. Soe \& Liisa R. (2012). Evaluation of Entrepreneurial Development Coaching: Changing the Teacher's Thinking and Action on Entrepreneurship. Annual of Innovation Entreptreneurship 3.

Awang Lokey \& M. Hasani Dali. (2016). Hubungan antara Kepimpinan Transformasional Guru Besar dengan Komitmen Guru Pendidika Pendidikan. Bil. 3, Isu 1

Anizam M. Y., Manisah M.A.\& Amla M. S.. (2013) Pendidikan Vokasional Pelajar Berkeperluan Khas Ke Arah Memenuhi Pasaran Pekerjaan. Proceeding of the International Conference on Social Science Research, IC ICSSR 2013. 4-5 June 2013, Penang, Malaysia. E-ISBN 978-11768-1-8.

Anizam M. Y., Manisah M. A., \& Salleh, Amla M. (2012). Penerapan Kemahiran Kebolehkerjaan dalam kalangan Pelajar Berkeperluan Khas. Paper presented at the Seminar Kebangsaa Puteri Pasific, Johor Bahru.

Airulliza. (2012). Pengaruh minat dalam amalan motivasi terhadap pembelajaran pelajar-pelajar tingkatan empat. Universiti Pendidikan Sultan dris.

Cameron, H. \& Nunkoosing, K. (2012). Lecturer within one on dyslexia and dyslexic Studen Teaching in Higher Education, 17(3), 341-352
Fleming A.R \& Fairweather J.S. (2012). The Role of Postsecondary Education in the Path From High School to Work for Youth With Disabilities. Caree Development and Transition for Exceptional Individuals 2012 35: 132

Hollins, E.R. (2011). Teacher Preparation For Quality Teaching. Journal of Teacher Education. 62 (4). $395-407$

Haznurah Zainon \& Mohd Zuri Ghani. (2012). Tekanan emosi guru pendidikan khas di sekolah. Journal of Special Needs Education, Volume 2, 2012, Pages 138 to 149.

Jabatan Pembangunan Kemahiran. (2012). Panduan Pelaksanaan Dan Syarat Pentauliahan Pusat Bertauliah Di Bawah Sistem Persijilan Kemahiran Malaysia Berasaskan Standard Kemahiran Pekerjaan Kebangsaan 2012. Kementerian Sumber Manusia, Malaysia. 63

Jessica Jawing. (2012). Bangunan Harus Mesra OKU. Terbitan Borneo Post Online Sarawak: Malaysia.

Kementerian Pendidikn Malaysia. (2013). Pelan Pembangunan Pendidikan Malaysia 2013-2025. Pembangunan Pendidikan Malaysia 2013-2025.
Putrajaya Malaysia; Kementerian Pendidikan Malaysia. www.moe.gov.my

Kementerian Pelajaran Malaysia. (2012). Laporan Awal Pelan Pembangunan Pendidikan Malaysia 2013-2025.

Kementerian Pengajian Tinggi Malaysia. (2011). Perangkan Pengajin Tinggi Malaysia Penyelidikan KPT.

Melissa, Ng L., Yen, Abdullah, \& See, Ching M., (2011). Employment of people with disabilities in Malaysia: Drivers and inhibitors. International Journal of Special Education, 26(1), 112-124 Pelan Strategik Interim 2012. Kementerian 2017 daripada http;//www.moe.gov.my/pdf

Mohd H. A., (2008). Persepsi Pensyarah Institut Perguruan Gaya Terhadap Tahap Penguasaan dan Gena Ken ICT. Guma 1:81-100

Mohd M. K.,(1990). Kaedah Penyelidikan Pendidikan. Kuala Lumpur: Dewan Bahasa \& Pustaka

Mohd. S., Mohd. R. and Arshad, M. (2010). Masalah Guru Pendidikan Khas Program Integrasi Dalam Pengajaran Dan Pembelajaran Kemahiran Hidup Di Sekolah Menengah, Daerah Kota Tinggi, Johor. Masalah Guru Pendidikan Khas Program Integrasi Dalam Pengajaran Dan Pembelajaran Kemahis Dan Help Disekola Menengah, Dera Kota Tinggi.
Noraini I., (2013). Education for All Malaysian perspective. Selangor; Seri Kembangan.

Norfadhilah N., (2014). Penilaian Pencapaian Objektif program pembudayaan keusahawanan (PPK) di Politeknik Malaysia. Tesis Dr. Fal. Universiti Kebangsaan Malaysia.

Noraini A., Mohd H., Mohd Y., \& Nur, A. (2015). Vocational Education as a Career Pathway for Students with Learning Disabilities: Issues and Obstacles in the Implementation. International Journal of Education and Social Science 2(3): 98-104.

Noor Aini, Zamri dan Zahara. (2012). Pengajaran kemahiran komunikasi bagi murid-murid bermasalah pembelajaran teruk. Jurna

Shahrina H. \& Siti H. M., (2010). Faktor penghalang penerapan ciri keusahawanan dalam pengajaran dan pembelajaran di sekolah mengikut perspektif guru. Institutional Repository. UTM. 